\title{
Imagining things otherwise: new endgame ideas for tobacco control
}

\section{Ruth E Malone}

Where are we going in tobacco control long-term, and how will we get there? This issue of Tobacco Control features three new contributions to the growing 'endgame' literature with possible answers to those questions: big-picture radical ideas that seek to propel the tobacco control movement more quickly towards a time when the global tobacco disease pandemic that began in the 20th century will be ended. Could the multitude of social structures and institutions that sustain the tobacco problem be unlinked? Could altered market forces-price controls, supply controls-render tobacco less attractive to those who profit most from continuing to addict new generations? Could there come a time when cigarettes - the most deadly consumer product ever made-will no longer be commercially sold? Can a stake someday be driven through the heart of the tobacco industry?

Endgame thinkers are the visionaries of the tobacco control movement. Early contributions to this literature, many of which were first published in this journal, included Borland's regulated market model ${ }^{1}$; Callard, Thompson and Collishaw's work on restructuring the industry so that it was incentivised to reduce consumption ${ }^{2}$; and calls for phasing out smoked tobacco products through various approaches. ${ }^{3-5}$ Others in this broad genre of work include Chapman's ${ }^{6}$ call for licensing smokers, work on nicotine and other types of ingredient regulation to render cigarettes less or non-addictive, ${ }^{7} 8$ and other 'big picture' ideas. ${ }^{9}$ Increasingly, the idea that tobacco control is fundamentally a systems problem is becoming a part of global discussions. ${ }^{10}$ Major tobacco control programme successes also suggest that changing what tobacco use (and the tobacco industry) means is foundational to ending the global pandemic. ${ }^{11} 12$

Correspondence to Ruth E Malone, Professor of Nursing and Health Policy, Department of Social and Behavioral Sciences, University of California, San Francisco, 3333 California St Suite 455, San Francisco 94118, USA; ruth.malone@ucsf.edu
In this issue, Gilmore and colleagues ${ }^{13}$ argue that regulating prices of tobacco through capping of manufacturers' prices could reduce tobacco industry market power by eliminating manufacturers' ability to disguise price increases and achieve higher profits. As they point out, in higher-tax western countries, the industry's profits are increasing despite declining sales-profits that are then available to the industry to further promote tobacco use in the emerging markets of low-income countries. ${ }^{14}$ The thoughtful argument by Gilmore et al extends ongoing conversations about regulatory approaches to the tobacco market $^{1} 15$ and offers an incentive for governments to act: an increased share of the money.

Khoo and colleagues ${ }^{16}$ propose a unique idea: end tobacco sales for those born after a certain date. Rather than focusing on preventing tobacco sales to minors, with the implicitly attractive 'forbidden fruit' message such approaches cannot avoid, the authors argue that their proposal to end sales to anyone born after the year 2000 would minimise immediate impact on stakeholders and allow time for transitions, while being entirely congruent with the tobacco industry's assertions that they now seek to market only to existing smokers and not to youth. Interestingly, the authors' preliminary work suggests strong public support for such an idea. Of course, Singapore is somewhat unique in its regulatory climate, but the idea offers a fresh perspective on 'youth access'.

Addressing issues of supply is the focus of the proposal by Thomson et al ${ }^{17}$ for a 'sinking lid' on the commercial supply of tobacco, with quotas reduced gradually over a period of 10 years. Government-run auctions, such as those which have been used for other types of policies, would draw manufacturers to bid for a gradually decreasing amount of tobacco. If successful, they argue, such a system would increase the price of tobacco, contributing to reduced consumption. Combined with demand-reduction measures, such an approach could radically alter the tobacco control landscape within a country.

Could any of these latest big picture ideas really work? Perhaps not immediately, but they inspire us all to think beyond the next smoke-free ordinance or tobacco quitline. Perhaps they could not work in one country, but could be done in another-in one with more easily controlled borders, for example, in the New Zealand case, or in a country generally supportive of government regulation, as in the UK and Singapore.

It was through such visionary thinking that we began to understand that the suffering and death tobacco causes is not merely a problem of poor individual health behaviour choices, but of the rise of an entire industry focused on aggressively promoting deadly addictive products. It was through visionary thinking that we began to question whether breathing the smoke from others' cigarettes might be harmful to non-smokers. It is visionary thinking, combined with skilled advocacy, that pushes governments to act more decisively to protect the public and to rein in the activities of tobacco companies.

Every person who becomes newly involved in the tobacco control movement, whether as an activist, researcher, programme planner or health professional, remembers that first moment of realising: it doesn't have to be this way. Often, that realisation is coupled with the notion that cigarettes should just be banned, and incredulity that it has not already been done. Then, seasoned veterans explain the interlocking political, physiological, legal and economic webs that constrain such policy change. But the first step towards breaking through those webs is to rediscover our ability to imagine things otherwise.

The public may be more ready for radical changes than most policymakers recognise. Studies suggest there may be fairly strong support for ending tobacco sales. ${ }^{18-20}$ Earlier work drawing on tobacco industry documents showed that the industry's own survey data from the early 2000s in the US suggested that a majority wished 'there were some way to eliminate cigarettes', supported banning cigarette advertising and felt that the right and responsible thing for cigarette companies to do would be to phase out of the cigarette business. ${ }^{, 21}$ Imagining things otherwise helps us see how to head towards where the public (and any rational person whose livelihood does not depend upon the tobacco status quo) already sees we should eventually go. But 
the tobacco control problem remains at its core a political problem: How to get governments to take bigger-picture actions to protect public health when a powerful industry opposes measures that threaten profits?

If we fail to exercise our moral imaginations to envision radical change, we are abandoning future generations to suffer and die from the mistakes of the past. We must instead continue to wrestle with, critique, develop and advocate for new visions of tobacco control. It doesn't have to be this way.

Competing interests RM owns one share each of Philip Morris/Altria, Philip Morris International and Reynolds American Tobacco Company stock for research and advocacy purposes. She served as a tobacco documents consultant for the US Department of Justice in USA vs Philip Morris et al.

Contributors RM wrote the editorial.

Provenance and peer review Not commissioned; not externally peer reviewed.

Tobacco Control 2010;19:349-350.

doi:10.1136/tc.2010.039727

\section{REFERENCES}

1. Borland R. A strategy for controlling the marketing of tobacco products: a regulated market model. Tob Control 2003;12:374-82.
2. Callard C, Thompson D, Collishaw N. Transforming the tobacco market: why the supply of cigarettes should be transferred from for-profit corporations to non-profit enterprises with a public health mandate. Tob Control 2005;14:278-83.

3. Daynard RA. Doing the unthinkable (and saving millions of lives). Tob Control 2009;18:5.

4. Hall W, West R. Thinking about the unthinkable: a de facto prohibition on smoked tobacco products. Addiction 2008;103:873-4

5. Gartner C, McNeill A. Options for global tobacco control beyond the Framework Convention in Tobacco Control. Addiction 2010;105:1-3.

6. Chapman S, Liberman J. Ensuring smokers are adequately informed: reflections on consumer rights, manufacturer responsibilities, and policy implications. Tob Control 2005;14(Suppl 2):ii8-13.

7. Benowitz NL, Henningfield JE. Establishing a nicotine threshold for addiction-the implications for tobacco regulation. $N$ Engl J Med 1994;331:123-5.

8. Hatsukami DK, Perkins KA, LeSage $M$, et al. Nicotine reduction revisited: science and future directions. Tob Control 2010;19:436.

9. Laugesen M, Glover M, Fraser T, et al. Four policies to end the sale of cigarettes and smoking tobacco in New Zealand by 2020. N Z Med J 2010;123:55-67.

10. Borland R, Young D, Coghill K, et al. The tobacco use management system: analyzing tobacco control from a systems perspective. Am J Public Health 2010;100:1229-36.

11. Roeseler A, Burns D. The quarter that changed the world. Tob Control 2010;19(Suppl 1):i3-15.

12. Chapman S, Freeman B. Markers of the denormalisation of smoking and the tobacco industry. Tob Control 2008;17:25-31.
13. Gilmore AB, Branston JR, Sweanor D. The case for OFSMOKE: how tobacco price regulation is needed to promote the health of markets, government revenue and the public. Tob Control 2010;19:423-30.

14. Callard CD. Follow the money: how the billions of dollars that flow from smokers in poor nations to companies in rich nations greatly exceed funding for global tobacco control, and what might be done about it. Tob Control 2010;19:285-90.

15. Jha $\mathbf{P}$, Musgrove $\mathrm{P}$, Chaloupka FJ, et al. The economic rationale for intervention in the tobacco market. In: Jha P, Chaloupka FJ, eds. Tobacco Control in developing countries. Oxford: Oxford University Press, 2000:153-74.

16. Khoo D, Koong H-N, Berrick AJ, et al. Phasing-out tobacco: proposal to deny access to tobacco for those born from 2000. Tob Control 2010;19:355-60.

17. Thomson G, Wilson N, Blakely $\mathrm{T}$, et al. Ending appreciable tobacco use in a nation: using a sinking lid on supply. Tob Control 2010;19:431-35.

18. Thomson G, Wilson N, Edwards R. Kiwi support for the end of tobacco sales: New Zealand governments lag behind public support for advanced tobacco control policies. N Z Med J 2010:123:106-11.

19. Wilson N, Edwards R, Thomson G, et al. High support for a tobacco endgame by Pacific peoples who smoke: national survey data. N Z Med J 2010;123:131-4.

20. Shahab L, West R. Public support in England for a total ban on the sale of tobacco products. Tob Control 2010;19:143-7.

21. Yang JS, Malone RE. 'Working to shape what society's expectations of us should be': Philip Morris's societal alignment strategy. Tob Control 2008;17:391-8

\section{Call for papers}

2012 marks 20 years of publication of Tobacco Control. To celebrate this milestone, plans are underway for a special anniversary issue of the journal, to be published and distributed in conjunction with the next World Conference on Tobacco or Health in Singapore in 2012. The issue is envisioned as providing a snapshot of global tobacco control efforts at this moment in history, looking both backward at the progress made (and lessons learned in the process) and forward to the future of the next 20 years. In addition to commissioned papers on key topics, the editors invite open submission of papers, including: reviews of tobacco control topics not covered in previously published reviews; policy analyses of emerging issues in tobacco control; short commentaries providing a fresh perspective on tobacco control topics.

Send abstracts and a short cover letter to the editorial office, email: tobaccocontrol@bmjgroup. com. Closing date-15 November 2010.

All submissions will be reviewed by the senior editorial team and a limited number will be invited to submit full papers, which will be due no later than April 1, 2011. Papers not selected for the special issue may be invited to submit for regular issues. All manuscripts will be peer reviewed. Please consider contributing your good ideas to help make this a landmark publication that will serve as a tobacco control resource. 